\title{
EFFECTS OF LYSINE-INDUCED ACUTE RENAL FAILURE IN DOGS
}

\author{
Kentaro ASANUMA, Kenji ADACHI, Tetsuro SUGIMOTO and Shuichi CHIBA \\ Safety Assessment Department, Chugai Pharmaceutical Co., Ltd., \\ 1-135 Komakado, Gotemba-shi, Shizuoka 412-8513, Japan
}

(Received November 3, 2005; Accepted December 24, 2005)

\begin{abstract}
This study investigates the effects of lysine-induced acute renal failure. Female dogs received a lysine hydrochloride (lysine) of $4500 \mathrm{mg} / \mathrm{kg} /$ day $(3.75 \mathrm{ml} / \mathrm{kg} / \mathrm{hr}$ ) for 3 consecutive days. The dogs were observed for clinical signs. Body weights were recorded, food consumption and water consumption calculated, and urinalysis and blood biochemistry were performed daily. Plasma samples for amino acid determinations were obtained from all dogs, which were necropsied on Day 3. Histopathological examinations were done on all test animals. Compound-related findings include the following. Blood biochemistry results showed increases in ammonia, blood urea nitrogen, blood urea nitrogen/creatinine ratio, and creatinine. Urinary changes consisted of increases in urine volume, total protein, albumin, $\gamma-$ glutamyl transpeptidase, and $N$-acetyl- $\beta$-D-glucosaminidase. In addition, macroscopic findings consisted of pale, congested capsule; microscopic findings consisted of hypertrophy of proximal convoluted tubule (mainly S1 segment), and degeneration/desquamation of urinary tubule (mainly S3 segment with hyaline casts) in the kidney. From these findings, it can be concluded that lysine is nephrotoxic in dogs. Nephrotoxicity of lysine may relate to direct tubular toxicity and to tubular obstruction.
\end{abstract}

KEY WORDS: Lysine, Acute renal failure, Kidney, Dogs, Urinary tubule obstruction, Continuous intravenous infusion

\section{INTRODUCTION}

Lysine was first isolated in 1889 from a milk byproduct. The structure was elucidated in 1902 and the compound synthesized. Lysine as an essential amino acid for growth in humans was shown in 1949 (Zweig, 1973). From amino acid toxicity, increased blood urea nitrogen (BUN) and ammonia will result in a few days (Hayashi et al., 1992; Horio and Orita, 1999; Ikeda et al., 1995). Although it was found that administration of amino acid causes an increase in BUN transiently, this change is unrelated to acute renal failure and considered to show that the promotion of the urea cycle was observed as an action of amino acid (Sanjo et al., 1991). However, substantial research on lysine was carried out by an animal experiment that used rats, and there are almost no experiments using dogs. In fact, it has been reported that amino acid induced acute renal failure in rats (Malis et al., 1984; Racusen et al., 1985a, 1985b; Zager et al., 1983; Zager and Venkatachalam, 1983; Weinberg, 1990). In particular, lysine-induced acute renal failure was reported in rats. In addition, there have been two reports showing lysine-induced acute renal failure in dogs. Although Gougoux et al. (1978) reported that the glomerular filtration rate (GFR) was decreased by $3 \mathrm{hr}$ of lysine infusion in dogs; this was not a morphology study. Newburgh and Marsh (1925) also reported lysine-induced acute renal failure in dogs; urine casts appeared in 3 urine specimens and granular degeneration of epithelium in convoluted tubules as morphologic changes was observed following $48 \mathrm{hr}$ of lysine infusion. However, the details were not reported and other examinations (urinalysis, blood biochemistry, and pathological examination) were not performed in either of these reports. In addition to the saline as control, in this study, Morihepamin as an amino acid solution was used for comparison with lysine. In this study, in order to distinguish change produced according to kidney obstructions and change observed by amino acid infusion relevant to change observed by lysine, the Morihepamin group was set up. The purpose of this investigation was to evaluate the

Correspondence: Kentaro ASANUMA (E-mail: asanumaknt@chugai-pharm.co.jp) 
effects of lysine-induced acute renal failure in dogs from a general toxicity examination (clinical signs, food consumption, water consumption, body weights, urinalysis, blood biochemistry, plasma amino acid concentration, autopsy and histopathology).

\section{MATERIALS AND METHODS}

\section{Animals and housing conditions}

Twelve 7-month-old female dogs (Beagle/CSK) obtained from CSK Research Park Co., Ltd. (Suwa, Japan) were used in this study. The dogs were housed one per cage and acclimatized in the animal facility for at least one week before use and were maintained during the study in standard conditions (12-hr light/12-hr dark cycle, $22 \pm 2^{\circ} \mathrm{C}$ temperature, and $55 \pm 10 \%$ relative humidity). Animals were fed a CD-5 pellet diet (CLEA Japan, Inc., Shizuoka, Japan) at 250 g/day/dog and tap water ad libitum. All procedures associated with this study were received and approved by the Institutional Animal Care and Use Committee and were performed according to the Guide for the Care and Use of Laboratory Animals of the Institute of Laboratory Animal Resources.

\section{Chemicals}

Lysine hydrochloride was purchased from Ajinomoto Co., Inc. (Tokyo, Japan). Dosing solutions of lysine hydrochloride were dissolved in water for injection (Otsuka Pharmaceutical Factory Inc., Tokushima, Japan) at concentrations of $62.45 \mathrm{mg} / \mathrm{ml}$ under sterile conditions. Morihepamin (total amino acid solution for injection) was purchased from Ajinomoto Pharma Co., Ltd. (Tokyo, Japan). The composition of Morihepamin is given in Table 1. Saline solution was purchased from Terumo Corporation (Tokyo, Japan).

\section{Surgery}

The dogs used in this study underwent the standard acclimatization period for one week at our animal facility before surgery. The dogs were then preanesthetized with $0.05 \mathrm{mg} / \mathrm{kg}$ atropine sulfate (Tanabe Seiyaku Co., Ltd., Osaka, Japan), and anesthetized with $30 \mathrm{mg} /$ $\mathrm{kg}$ pentobarbital sodium (Dainippon Pharmaceutical Co., Ltd., Osaka, Japan) given intramuscularly and intravenously, respectively. All subsequent procedures were performed using standard aseptic surgical techniques. An indwelling 6-French polyurethane catheter (0.6-mm ID $\times 0.9-\mathrm{mm}$ OD, Toray Industries, Inc., Tokyo, Japan) and medical grade silicone tubing (2mm ID × 4-mm OD, Norton Co., Akron, OH, USA) were implanted into the posterior vena cava by introduction through a femoral vein and then threaded under the skin to exit from the dorsal neck region. A jacket placed around the thorax of the animal covered the exit site of the catheter in the nape of the neck. The exposed catheter was protected with a tether (Lomir Biomedical Inc., Canada) and swivel (Lomir Biomedical Inc.). The swivel was mounted in the door of the cage. The swivel was then connected via silicone tubing (2-mm ID $\times 4$-mm OD, Norton Co.), with an infusion line (Terumo Corporation) to a $0.22 \mu \mathrm{m}$ filter (Millipore Japan Co., Ltd., Tokyo, Japan), which was connected to an infusion bag. The implanted dogs were maintained on continuous infusion with sterile saline (Terumo Corporation) at a rate of $10 \mathrm{ml} /$ body/hr using an infusion pump (TE-171, Terumo Corporation) until termination.

As post-operative treatment, povidone iodine (Meiji Seika Kaisha, Ltd., Tokyo, Japan) was applied on wound surfaces once daily and the animals were treated with $5 \mathrm{mg} / \mathrm{kg}$ orbifuloxacin (Dainippon Pharmaceutical Co., Ltd.) given intramuscularly twice daily for 2 days after surgery.

\section{Experimental design}

Following the 14-day recovery period after surgery, the dogs were divided according to body weight into three different treatment groups with $4 \mathrm{dogs}$ in

Table 1. Composition of amino acid solution (Morihepamin).

\begin{tabular}{lc}
\hline Composition & Concentration $(\mathrm{g} / \mathrm{l})$ \\
\hline Total amino acid & 75.85 \\
L-Isoleucine & 9.20 \\
L-Leucine & 9.45 \\
L-Lysine acetate & 3.95 \\
L-Methionine & 0.44 \\
L-Phenylalanine & 0.30 \\
L-Threonine & 2.14 \\
L-Tryptophan & 0.70 \\
L-Valine & 8.90 \\
L-Alanine & 8.40 \\
L-Arginine & 15.37 \\
L-Aspartic acid & 0.20 \\
L-Histidine & 3.10 \\
L-Proline & 5.30 \\
L-Serine & 2.60 \\
L-Tyrosine & 0.40 \\
Glycine & 5.40 \\
\hline
\end{tabular}


Lysine-induced acute renal failure in dogs.

each group on Day -1 . The animals in the saline group (Animal Nos. 1-4) were infused with a saline $(\mathrm{pH}$ $6.34,283 \mathrm{mOsm}$ ) at $3.75 \mathrm{ml} / \mathrm{kg} / \mathrm{hr}$. The animals in the lysine group (Animal Nos. 9-12) were infused with a solution of $62.45 \mathrm{mg} / \mathrm{ml}$ lysine hydrochloride $(\mathrm{pH}$ $5.85,619 \mathrm{mOsm})$ at a rate of $3.75 \mathrm{ml} / \mathrm{kg} / \mathrm{hr}$. The animals in the Morihepamin group (Animal Nos. 5-8) were infused with $75 \mathrm{mg} / \mathrm{ml}$ of Morihepamin ( $\mathrm{pH} 7.23$, $743 \mathrm{mOsm}$ ) at a rate of $2.50 \mathrm{ml} / \mathrm{kg} / \mathrm{hr}$. For all groups, the duration of infusion was $72 \mathrm{hr}$ at a constant rate using an infusion pump (TE-171, Terumo Corporation). A high dose of L-lysine (1682 mg/kg/4 hr infusion) induced compound-related acute renal failure in rats (Racusen et al., 1985b). Our feasibility study results in dogs indicated that high-dose amino acid infusion (4500 mg/kg/day) could cause an increase in BUN and ammonia from Day 3 after the start of infusion. Therefore, dose, dose concentration, dosing volume and dosing speed of lysine and Morihepamin were set similar to our feasibility study in dogs.

\section{Clinical signs, body weights, food and water con- sumption}

Clinical signs, body weights, and food and water consumption for all dogs were monitored daily.

\section{Urinalysis}

Urine specimens were collected over a period of $24 \mathrm{hr}$ on Days 1, 2, and 3, stored on ice, and used for the following analyses. Daily urine weight and specific gravity were measured using an electronic balance (Shimadzu Corp.) and a urinometer (Atago Co., Ltd.), respectively, and used to calculate the 24-hr urine volume ( $\mathrm{ml} /$ day). The urinary concentrations and method of analysis of total protein (TP) (pirogar-red), albumin (ALB) (immuno-mix), $N$-acetyl- $\beta$-D-glucosaminidase (NAG) (MCP-NAG), leucine aminopeptidase (LAP) L-leucyl-p-nitroanilide) and $\gamma$-glutamyl transpeptidase (G-GTP) ( $\gamma$-glutamyl-CPA substrate) were measured using a 7170 auto-analyzer (Hitachi Ltd., Tokyo, Japan).

\section{Blood biochemistry}

Blood biochemistry analyses were performed on Days $-5,1,2$, and 3 . Blood samples of $5 \mathrm{ml}$ of nontreated blood and $2 \mathrm{ml}$ of EDTA/2NA blood were collected from the cephalic vein of each dog after an overnight fast. Non-treated blood samples were allowed to stand for $30 \mathrm{~min}$ at room temperature, centrifuged $\left(1870 \times \mathrm{g}, 4^{\circ} \mathrm{C}, 10 \mathrm{~min}\right)$, and the separated serum stored at $-80^{\circ} \mathrm{C}$. EDTA/2NA blood samples were stored on ice, centrifuged $\left(1870 \times \mathrm{g}, 4^{\circ} \mathrm{C}, 10 \mathrm{~min}\right)$, plasma separated, and ammonia measured immediately. Separated samples were used for the following analyses and methods.

BUN (urease-GLDH), creatinine (CRN) (enzyme), ammonia (enzyme), TP (Biuret's), and ALB (BCG) were determined using a Hitachi 7170 autoanalyzer (Hitachi Ltd.). The BUN/CRN ratio and Alb/ globulin ratio were calculated.

\section{Determination of plasma amino acid concentration}

Plasma amino acid concentration was measured on Day 3. Blood samples for the determination of plasma amino acid concentration were obtained from 4-dogs/sampling point on Day 3 in each group. Blood samples of $2 \mathrm{ml}$ were collected into heparinized syringes from the cephalic vein and put on ice and then centrifuged $\left(1900 \times \mathrm{g}, 4^{\circ} \mathrm{C}, 10 \mathrm{~min}\right)$. The resulting plasma samples were immediately frozen at $-30^{\circ} \mathrm{C}$ and kept frozen pending quantification of plasma amino acid. After deproteinization by sulfosalicyclic acid, plasma amino acids were analyzed using a high-speed amino acid analyzer (Hitachi Ltd.). All endogenous and exogenous amino acids were measured.

\section{Pathology}

On Day 3, all dogs were euthanized by exsanguinations under general anesthesia with pentobarbital sodium (Dainippon Pharmaceutical Co., Ltd.), autopsied and kidney weight measured using an electronic balance (Shimadzu Corp.). The relative organ weight of the kidney per $100 \mathrm{~g}$ final body weight was calculated. The kidney was then fixed in $20 \%$ neutral buffered formalin. The fixed organ was embedded in paraffin, sectioned, double-stained with hematoxylin-eosin and examined under a light microscope.

\section{Statistical analysis}

Statistical analysis was performed using SAS preclinical package software (SAS version 8.2, SAS Institute Japan Inc., Tokyo, Japan). Parametric data such as body weight, food consumption, water consumption, urinalysis, blood biochemistry and organ weights were analyzed by the F test (Snedecor and Cochran, 1967). When homogeneity was observed, the Student's $t$-test (Steel and Torrie, 1980) was conducted and, when not found, the Aspin-Welch's $t$ test (Snedecor and Cochran, 1967) was performed. A value of $p<0.01$ or 0.05 was considered to be statistically significant. 


\section{RESULTS}

\section{Clinical signs, body weights, food and water con- sumption}

The results of clinical signs and food and water consumption are given in Table 2 and Fig. 1. In the lysine group, vomiting was observed in all animals from Day 1 or 2; constipation and decrease of stool were observed in all animals from Day 2 or 3; decrease of locomotor activity was observed in all animals on Day 3. No abnormalities in the observation of clinical signs were observed in any of the animals in the saline or Morihepamin group.

The body weights (mean \pm S.D.) at the start of experiment (Day -1) were $9.5 \pm 1.0 \mathrm{~kg}$ in the saline group, $9.3 \pm 0.4 \mathrm{~kg}$ in the Morihepamin group, and 9.3 $\pm 0.3 \mathrm{~kg}$ in lysine group. At the end of the experiment (Day 3) the body weights were $10.0 \pm 1.2 \mathrm{~kg}, 10.1 \pm$ $0.3 \mathrm{~kg}$, and $9.0 \pm 0.4 \mathrm{~kg}$, respectively. No statistically significant changes were observed in body weights of any one group.

No statistically significant changes were observed in the food consumption of any of the groups.
Individually, food consumption decreased in all animals on Day 2 in the lysine group. Moreover, none of the food supplied on Day 3 was consumed in the lysine group. No statistically significant change was observed in water consumption in all groups; however, water consumption clearly increased in all animals on Days 2 and 3 in the lysine group.

\section{Urinalysis}

Urinalysis results are summarized in Fig. 2. In the lysine group, urine volume increased to $2462 \pm 363 \mathrm{ml} /$ day on Day 2 and $4179 \pm 1506 \mathrm{ml} /$ day on Day 3. In the saline group, urine volume on Days 2 and 3 were $897 \pm$ 274 and $854 \pm 97 \mathrm{ml} /$ day, respectively. Urine specific gravity on Day 1 for the lysine group was $1.025 \pm$ 0.004 and for the saline group, $1.014 \pm 0.001$.

In the lysine group, TP increased to $34.5 \pm 20.9$ $\mathrm{mg} / \mathrm{dl}$ on Day 1 and to $78.3 \pm 46.2 \mathrm{mg} / \mathrm{dl}$ on Day 2. In the saline group, TP on Days 1 and 2 were $0.8 \pm 0.6$ and $0.2 \pm 0.3 \mathrm{mg} / \mathrm{dl}$, respectively. Although there were no significant differences, in the lysine group, TP increased to $46.7 \pm 70.4 \mathrm{mg} / \mathrm{dl}$ on Day 3 compared with the saline group $(0.1 \pm 0.3 \mathrm{mg} / \mathrm{dl})$, ALB increased

Table 2. Clinical signs of the lysine group.

\begin{tabular}{|c|c|c|c|c|c|}
\hline Animal Nos. & Findings & Before & Day 1 & Day 2 & Day 3 \\
\hline \multirow[t]{5}{*}{9} & No abnormality & + & - & - & - \\
\hline & Decrease of locomotor activity & - & - & - & + \\
\hline & Vomiting & - & + & + & + \\
\hline & Constipation & - & - & - & + \\
\hline & Decrease of stool & - & - & + & - \\
\hline \multirow[t]{5}{*}{10} & No abnormality & + & - & - & - \\
\hline & Decrease of locomotor activity & - & - & - & + \\
\hline & Vomiting & - & + & + & + \\
\hline & Constipation & - & - & - & + \\
\hline & Decrease of stool & - & - & + & - \\
\hline \multirow[t]{5}{*}{11} & No abnormality & + & + & - & - \\
\hline & Decrease of locomotor activity & - & - & - & + \\
\hline & Vomiting & - & - & + & + \\
\hline & Constipation & - & - & - & + \\
\hline & Decrease of stool & - & - & + & - \\
\hline \multirow[t]{5}{*}{12} & No abnormality & + & + & - & - \\
\hline & Decrease of locomotor activity & - & - & - & + \\
\hline & Vomiting & - & - & + & + \\
\hline & Constipation & - & - & + & - \\
\hline & Decrease of stool & - & - & - & + \\
\hline
\end{tabular}

+: Observed; -: Not observed. Before: before start of infusion on Day 0; Day 1: 1 day after start of infusion; Day 2: 2 days after start of infusion; Day 3: 3 days after start of infusion. No abnormalities were observed for Days 1-3 in the saline group (Animal Nos. 1-4) and the Morihepamin group (Animal Nos. 5-8). 
Lysine-induced acute renal failure in dogs.

to $206 \pm 173,338 \pm 394$, and $277 \pm 552 \mu \mathrm{g} / \mathrm{ml}$ from Day 1 through Day 3 compared with the saline group ( $4 \pm 1,5 \pm 2$, and $1 \pm 2 \mu \mathrm{g} / \mathrm{ml}$ ). In the lysine group, GGTP increased to $29.8 \pm 9.5 \mathrm{IU} / \mathrm{l}$ on Day 1 compared with the saline group $(5.7 \pm 2.1 \mathrm{IU} / \mathrm{l})$, and NAG increased to $7.21 \pm 1.91 \mathrm{U} / \mathrm{l}$ on Day 1 and $4.88 \pm 0.88$ U/1 on Day 2. In the saline group, NAG on Days 1 and 2 were $1.52 \pm 0.19$ and $1.40 \pm 0.54 \mathrm{U} / 1$, respectively.

In the Morihepamin group, urine volume decreased to $500 \pm 104 \mathrm{ml} /$ day on Day 2 and $486 \pm 71$ $\mathrm{ml} /$ day on Day 3, urine specific gravity increased to $1.028 \pm 0.004$ on Day 2 and $1.028 \pm 0.004$ on Day 3, and NAG increased to $2.66 \pm 0.40 \mathrm{U} / 1$ on Day 3. No abnormality was observed in LAP in any of the groups.

\section{Blood biochemistry}

Table 3 summarizes the blood biochemistry data. In the lysine group, there was increased BUN from

\section{A Food consumption}

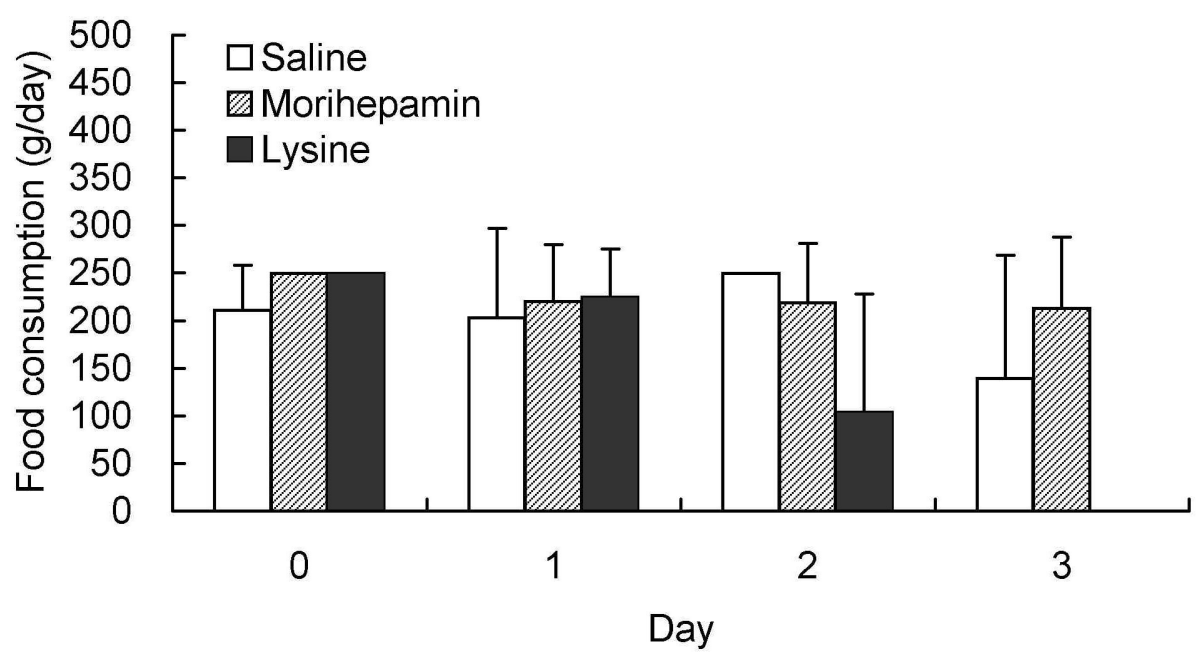

B Water consumption

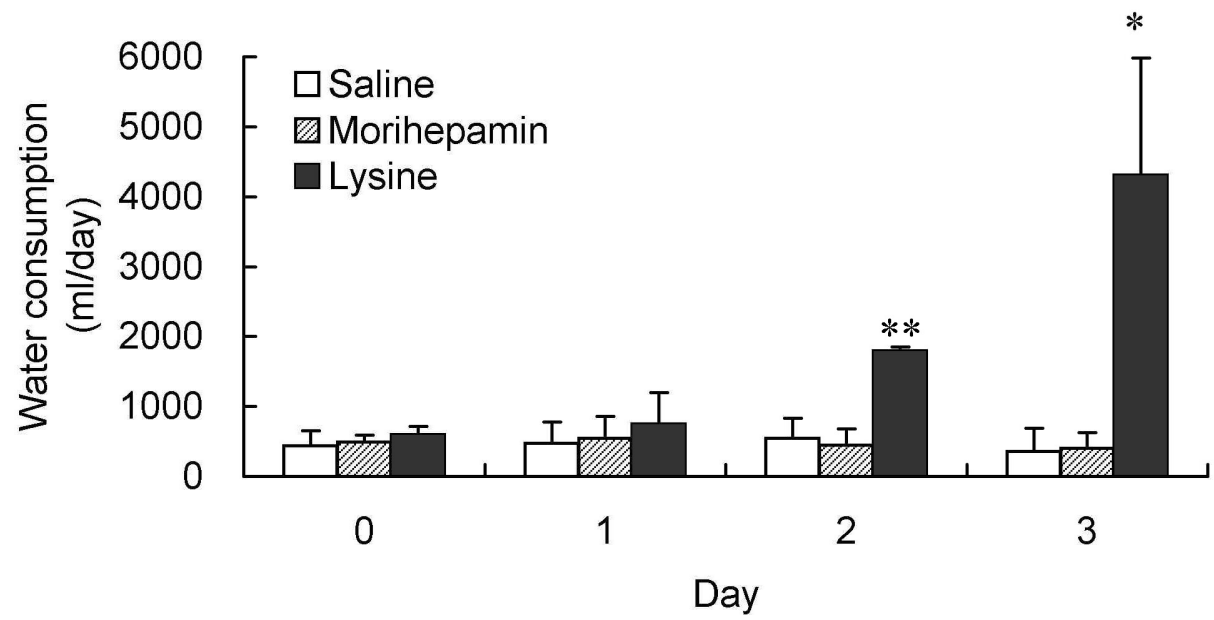

Fig. 1. Changes in food consumption (A) and water consumption (B). Values are the mean \pm S.D. $(\mathrm{n}=4) . * \mathrm{p}<0.05$ or $* * \mathrm{p}<0.01$; significant difference between the saline group and Morihepamin or lysine group. 
Day 1 to Day 3, increased ammonia from Day 1 to Day 2 , increased CRN from Day 2 to Day 3, an increase in the BUN/CRN ratio on Days 1 and 3, and a decrease in the albumin/globulin ratio on Day 3 in the lysine group. In the Morihepamin group, an increase in the BUN/CRN ratio from Day 1 to Day 3 and increased BUN from Day 1 to Day 3 was observed. No abnormality was observed in the saline group.

\section{A Urine volume}
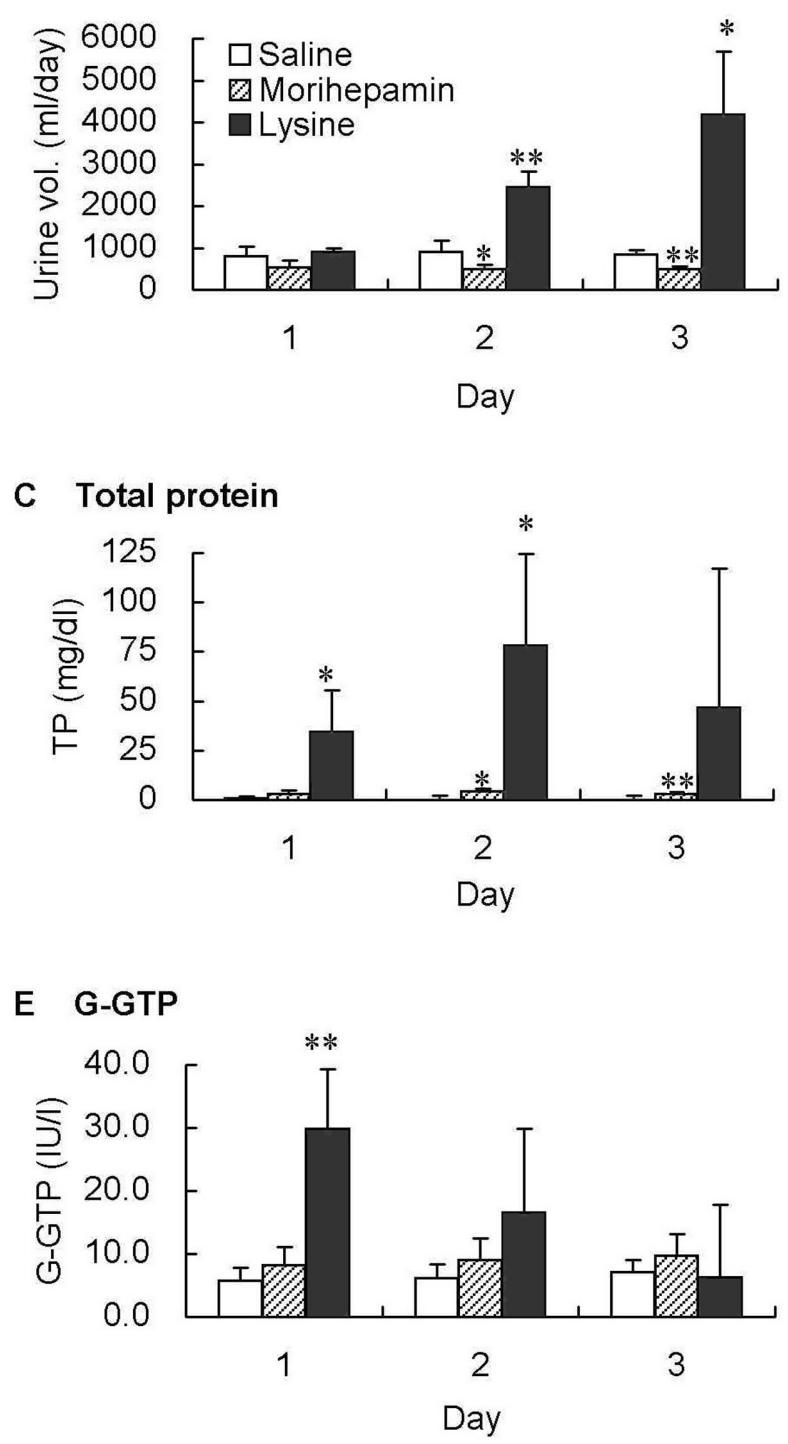

\section{Determination of plasma amino acid concentration}

Results of amino acid concentration in plasma are summarized in Table 4, compared to the base values of the saline group. In the Morihepamin group, compared with the saline group, more than a two-fold increase in proline, valine, isoleucine, leucine, ornithine, and arginine was observed. In the lysine group, the lysine concentration was $3365 \pm 1463 \mu \mathrm{g} / \mathrm{ml}$ on Day 3 and was about 140 times the lysine concentra-

\section{B Specific gravity}

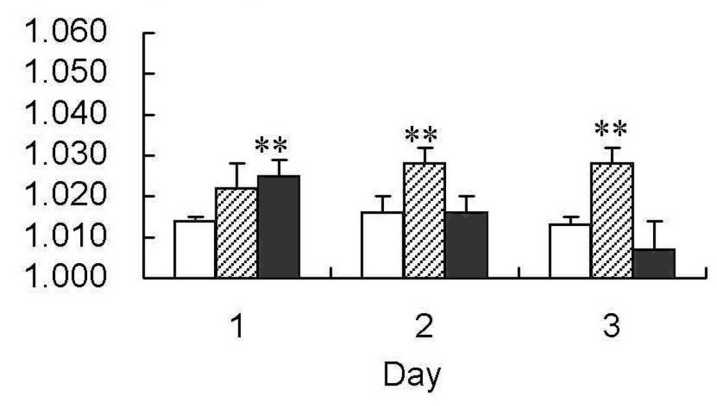

D Albumin

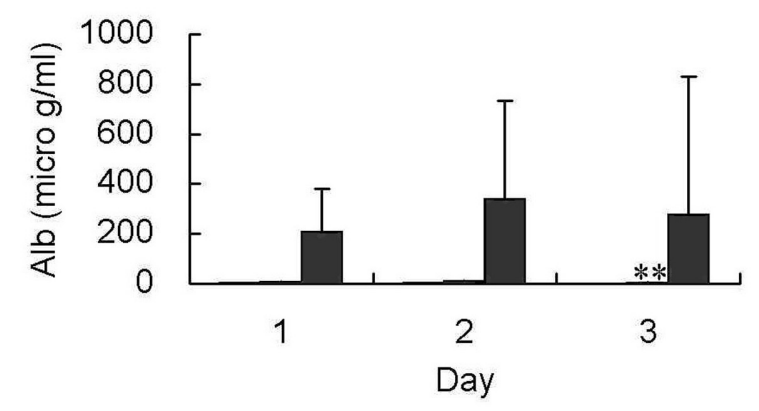

F NAG

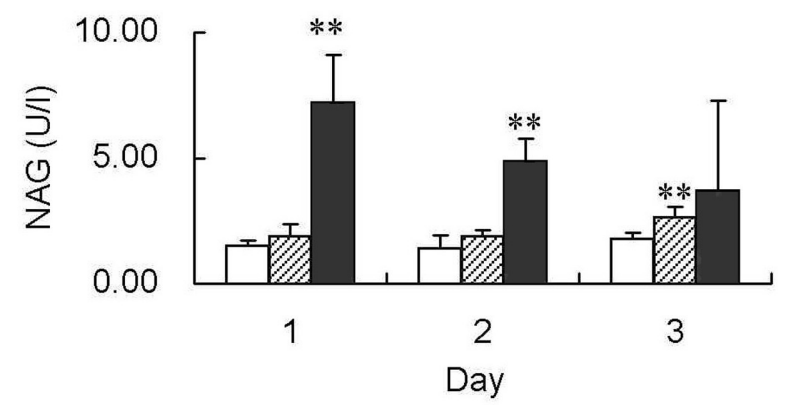

Fig. 2. Changes in urinalysis. Values are the mean \pm S.D. $(n=4)$. Urine volume $(A)$, specific gravity $(B)$, total protein $(C)$, albumin (D), $\gamma$-glutamyl transpeptidase (G-GTP) (E) and $N$-acetyl- $\beta$-D-glucosaminidase (NAG) (F). ${ }^{*} \mathrm{p}<0.05$ or $* * \mathrm{p}<0.01$; significant difference between the saline group and Morihepamin or lysine group. 
Lysine-induced acute renal failure in dogs.

tion in plasma of the saline group. Moreover, in the lysine group and compared with the saline group, more than a two-fold increase in threonine, serine, glutamine, glycine, citrulline, leucine, ornithine, histidine, and arginine were observed.

\section{Pathology}

Results of the microscopic findings are summarized in Table 5 and shown in Photo 1. In the lysine group, compound-related macroscopic findings were limited to a pale color in one animal, congestion in capsule in two animals, a dark red area in lung bronchi of all animals, insufficient retraction in lung bronchi of two animals, foamy substance in trachea of one animal, clot in heart of three animals, dark red area and recessed area in the funds of stomach mucosa of one animal, yellowish area in liver of three animals, atrophy in thymus of all animals, and dry subcutaneous tissue of two animals. In the Morihepamin group, no compound-related macroscopic findings were observed.

The Morihepamin group showed an increase in the absolute kidney weight at the end of the infusion period. No abnormal changes were observed in absolute kidney weight of the saline or lysine group. However, in the lysine group, a non-significant increase was observed individually.

In histopathology, hypertrophy of the proximal tubule (mainly the S1 segment) was observed in two animals of the Morihepamin group. Hypertrophy of the

Table 3. Blood biochemistry.

\begin{tabular}{|c|c|c|c|c|c|}
\hline \multicolumn{2}{|l|}{ Item } & Saline & Morihepamin & \multicolumn{2}{|c|}{ Lysine } \\
\hline \multirow[t]{4}{*}{ Blood urea nitrogen (mg/dl) } & Day -5 & $7.0 \pm 1.4$ & $7.2 \pm 0.7$ & $7.1 \pm$ & 1.5 \\
\hline & Day 1 & $6.1 \pm 1.0$ & $16.0 \pm 1.6^{* *}$ & $10.7 \pm$ & $1.4 * *$ \\
\hline & Day 2 & $7.2 \pm 1.5$ & $17.3 \pm 2.1 * *$ & $26.7 \pm$ & $11.2 *$ \\
\hline & Day 3 & $6.2 \pm 1.5$ & $17.9 \pm 1.3^{* *}$ & $43.9 \pm$ & $16.4 *$ \\
\hline \multirow[t]{4}{*}{ Creatinine $(\mathrm{mg} / \mathrm{dl})$} & Day -5 & $0.57 \pm 0.07$ & $0.58 \pm 0.04$ & $0.57 \pm$ & 0.06 \\
\hline & Day 1 & $0.55 \pm 0.06$ & $0.51 \pm 0.05$ & $0.62 \pm$ & 0.12 \\
\hline & Day 2 & $0.57 \pm 0.06$ & $0.50 \pm 0.06$ & $1.18 \pm$ & $0.15 * *$ \\
\hline & Day 3 & $0.53 \pm 0.06$ & $0.50 \pm 0.04$ & $2.17 \pm$ & $0.66^{*}$ \\
\hline \multirow[t]{4}{*}{ Blood urea nitrogen/creatinine ratio } & Day -5 & $12.3 \pm 1.6$ & $12.4 \pm 1.5$ & $12.5 \pm$ & 1.6 \\
\hline & Day 1 & $11.2 \pm 1.9$ & $31.6 \pm 3.3^{* *}$ & $17.6 \pm$ & $1.5^{* *}$ \\
\hline & Day 2 & $12.9 \pm 3.7$ & $34.8 \pm 4.0^{* *}$ & $22.1 \pm$ & 6.9 \\
\hline & Day 3 & $11.6 \pm 1.9$ & $36.1 \pm 2.3 * *$ & $19.9 \pm$ & $1.8 * *$ \\
\hline \multirow[t]{4}{*}{ Ammonia $(\mu \mathrm{g} / \mathrm{dl})$} & Day -5 & $19 \pm 12$ & $20 \pm 9$ & $31 \pm$ & 8 \\
\hline & Day 1 & $32 \pm 14$ & $36 \pm 13$ & 59 & $12 *$ \\
\hline & Day 2 & $28 \pm 8$ & $31 \pm 6$ & 104 & $26 * *$ \\
\hline & Day 3 & $25 \pm 5$ & $53 \pm 33$ & $258 \pm$ & 128 \\
\hline \multirow[t]{4}{*}{ Total protein $(\mathrm{g} / \mathrm{dl})$} & Day -5 & $6.41 \pm 0.45$ & $6.26 \pm 0.26$ & $6.32 \pm$ & 0.28 \\
\hline & Day 1 & $6.16 \pm 0.41$ & $6.17 \pm 0.18$ & $6.40 \pm$ & 0.30 \\
\hline & Day 2 & $6.26 \pm 0.33$ & $6.00 \pm 0.21$ & $6.76 \pm$ & 0.73 \\
\hline & Day 3 & $6.18 \pm 0.33$ & $6.08 \pm 0.14$ & $6.36 \pm$ & 0.28 \\
\hline \multirow[t]{4}{*}{ Albumin (g/dl) } & Day -5 & $3.32 \pm 0.16$ & $3.27 \pm 0.17$ & $3.23 \pm$ & 0.14 \\
\hline & Day 1 & $3.24 \pm 0.20$ & $3.28 \pm 0.04$ & $3.30 \pm$ & 0.21 \\
\hline & Day 2 & $3.29 \pm 0.14$ & $3.22 \pm 0.04$ & $3.42 \pm$ & 0.18 \\
\hline & Day 3 & $3.27 \pm 0.24$ & $3.29 \pm 0.04$ & $3.12 \pm$ & 0.06 \\
\hline \multirow[t]{4}{*}{ Albumin/globulin ratio } & Day -5 & $1.09 \pm 0.12$ & $1.10 \pm 0.11$ & $1.06 \pm$ & 0.12 \\
\hline & Day 1 & $1.11 \pm 0.08$ & $1.14 \pm 0.07$ & $1.07 \pm$ & 0.11 \\
\hline & Day 2 & $1.11 \pm 0.06$ & $1.16 \pm 0.10$ & $1.04 \pm$ & 0.14 \\
\hline & Day 3 & $1.12 \pm 0.07$ & $1.18 \pm 0.08$ & $0.97 \pm$ & $0.08 *$ \\
\hline
\end{tabular}

Values are the mean \pm S.D. $(n=4)$. Day $-5: 5$ days before start of infusion; Day 1: 1 day after start of infusion; Day 2: 2 days after start of infusion; Day 3: 3 days after start of infusion.

$* \mathrm{p}<0.05$ or $* * \mathrm{p}<0.01$; significant difference between the saline group and Morihepamin or lysine group. 
proximal tubule (mainly the S1 segment), and degeneration or desquamation of the urinary tubule with hyaline casts (mainly the S3 segment) was observed in all animals of the lysine group. Infusion-related histopathological findings include degeneration/regeneration of the proximal tubule (mainly the $\mathrm{S} 1$ segment) in one animal of the Morihepamin group.

\section{DISCUSSION}

Lysine is the only essential amino acid that has been reported to induce acute renal failure in rats (Malis et al., 1984; Racusen et al., 1985a, 1985b; Zager et al., 1983; Zager and Venkatachalam, 1983; Weinberg, 1990). This is the first report including tox-

Table 4. Plasma amino acid concentration.

\begin{tabular}{|c|c|c|c|c|c|c|}
\hline \multirow{3}{*}{$\begin{array}{c}\text { Amino acid } \\
\text { Taurine }\end{array}$} & \multicolumn{6}{|c|}{ Plasma amino acid concentration $(\mu \mathrm{g} / \mathrm{ml})$ on Day 3} \\
\hline & \multicolumn{2}{|c|}{ Saline } & \multicolumn{2}{|c|}{ Morihepamin } & \multicolumn{2}{|c|}{ Lysine } \\
\hline & 11.3 & \pm 2.1 & 12.6 & \pm 1.6 & $78.7 \pm$ & 46.4 \\
\hline Aspartic acid & 0.6958 & \pm 0.1994 & 0.743 & \pm 0.1469 IAA & \multicolumn{2}{|c|}{ N.D. } \\
\hline Threonine & 34.55 & \pm 4.83 & 29.99 & $\pm 7.64 \mathrm{IAA}$ & $92.20 \pm$ & $32.83 \uparrow_{2}$ \\
\hline Serine & 15.41 & \pm 2.11 & 21.98 & \pm 0.92 IAA & $38.51 \pm$ & $6.66 \uparrow_{2}$ \\
\hline Asparagine & 7.568 & \pm 1.097 & 4.582 & \pm 0.676 & \multicolumn{2}{|c|}{ N.D. } \\
\hline Glutamic acid & \multicolumn{2}{|c|}{ N.D. } & \multicolumn{2}{|c|}{ N.D. } & \multicolumn{2}{|c|}{ N.D. } \\
\hline Glutamine & 121.0 & \pm 19.5 & 133.7 & \pm 13.4 & $600.7 \pm$ & $176.2 \uparrow 2$ \\
\hline Proline & 15.04 & \pm 3.64 & 30.51 & $\pm 3.32 \uparrow 2$ IAA & \multicolumn{2}{|c|}{ N.D. } \\
\hline Glycine & 18.24 & \pm 4.60 & 28.86 & $\pm 3.39 \mathrm{IAA}$ & $59.79 \pm$ & $16.05 \uparrow_{2}$ \\
\hline Alanine & 34.85 & \pm 14.43 & 42.22 & \pm 8.94 IAA & $69.16 \pm$ & 38.67 \\
\hline Citrulline & 14.29 & \pm 5.59 & 17.92 & \pm 0.97 & $32.48 \pm$ & $9.18 \uparrow_{2}$ \\
\hline Valine & 17.74 & \pm 4.79 & 49.81 & $\pm 10.76 \uparrow 2$ IAA & \multicolumn{2}{|c|}{ N.D. } \\
\hline Cysteine & 2.874 & \pm 0.515 & 2.702 & $\pm 0.232 \mathrm{IAA}$ & \multicolumn{2}{|c|}{ N.D. } \\
\hline Methionine & 10.12 & \pm 1.19 & 8.051 & \pm 0.741 IAA & \multicolumn{2}{|c|}{ N.D. } \\
\hline Isoleucine & 8.338 & \pm 2.381 & 24.58 & $\pm 5.53 \uparrow 2 \mathrm{IAA}$ & \multicolumn{2}{|c|}{ N.D. } \\
\hline Leucine & 13.96 & \pm 3.92 & 30.03 & $\pm 7.02 \uparrow 2$ IAA & $75.14 \pm$ & $7.29 \uparrow 5$ \\
\hline Tyrosine & 7.474 & \pm 1.085 & 3.974 & $\pm 0.491 \mathrm{IAA}$ & \multicolumn{2}{|c|}{ N.D. } \\
\hline Phenylalanine & 9.490 & \pm 0.966 & 7.022 & $\pm 0.618 \mathrm{IAA}$ & \multicolumn{2}{|c|}{ N.D. } \\
\hline Tryptophan & 16.79 & \pm 1.56 & 19.18 & $\pm 2.96 \mathrm{IAA}$ & $14.68 \pm$ & 5.73 \\
\hline Ornithine & 2.689 & \pm 0.725 & 8.239 & $\pm 1.058 \uparrow_{2}$ & $21.73 \pm$ & $8.45 \uparrow 5$ \\
\hline Lysine & 24.37 & \pm 3.68 & 24.14 & $\pm 3.89 \mathrm{IAA}$ & \multicolumn{2}{|c|}{$3365 \pm 1463$ 个5 IAA } \\
\hline Histidine & 12.34 & \pm 0.86 & 20.38 & $\pm 0.78_{\mathrm{IAA}}$ & $54.88 \pm$ & $13.29 \uparrow_{2}$ \\
\hline Arginine & 24.75 & \pm 5.55 & 83.01 & $\pm 8.83 \uparrow_{2} \mathrm{IAA}$ & $92.29 \pm$ & $38.99 \uparrow_{2}$ \\
\hline
\end{tabular}

Values are the mean \pm S.D. $(n=4)$. Day 3: 3 days after start of infusion; N.D.: Not detected; $\uparrow 2$ : increased over 2-fold in the saline group; $\uparrow 5$ : increased over 5 -fold in the saline group; IAA: infused amino acid.

Table 5. Microscopic findings.

\begin{tabular}{|c|c|c|c|c|c|c|c|c|c|c|c|c|}
\hline \multirow[t]{2}{*}{ Findings } & \multicolumn{4}{|c|}{ Saline } & \multicolumn{4}{|c|}{ Morihepamin } & \multicolumn{4}{|c|}{ Lysine } \\
\hline & 1 & 2 & 3 & 4 & 5 & 6 & 7 & 8 & 9 & 10 & 11 & 12 \\
\hline \multicolumn{13}{|l|}{ Kidney } \\
\hline \multirow{2}{*}{$\begin{array}{l}\text { hypertrophy, proximal tubule } \\
\text { mainly S1 segment }\end{array}$} & 0 & 0 & 0 & 0 & 0 & 2 & 2 & 0 & 2 & 2 & 2 & 2 \\
\hline & & & & & & 2 & 2 & & 2 & 2 & 2 & 2 \\
\hline \multirow{2}{*}{$\begin{array}{l}\text { degenaration/regeneration, proximal tubule } \\
\text { mainly S1 segement }\end{array}$} & 0 & 0 & 0 & 0 & 0 & 0 & 0 & 1 & 0 & 0 & 0 & 0 \\
\hline & & & & & & & & 1 & & & & \\
\hline \multirow{2}{*}{$\begin{array}{l}\text { degenaration/desquamation, urinary tubule } \\
\text { mainly S3 segment, hyaline casts }\end{array}$} & 0 & 0 & 0 & 0 & 0 & 0 & 0 & 0 & 3 & 3 & 3 & 3 \\
\hline & & & & & & & & & 3 & 3 & 3 & 3 \\
\hline
\end{tabular}

0: no lesion; 1: very slight lesion; 2: slight lesion; 3: moderate lesion. 
Lysine-induced acute renal failure in dogs.
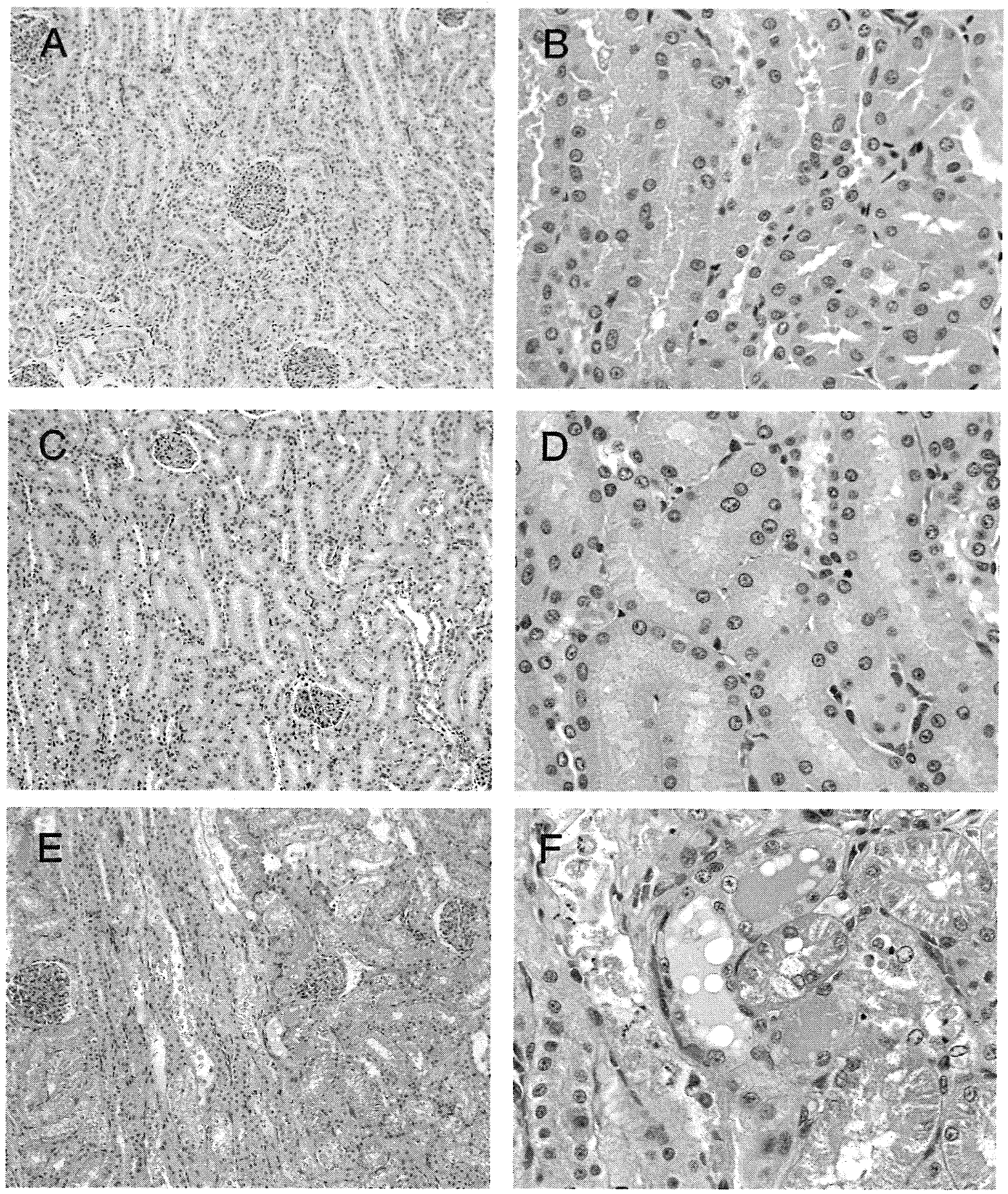

Photo 1. Light microscopic photographs (hematoxylin-eosin stain) in kidneys. Proximal tubules from the saline group $(\times 100)($ A), proximal tubules from the saline group $(\times 400)(B)$. Proximal tubules from the Morihepamin group, most tubules are abnormality dilated $(\times 100)(C)$, proximal tubule (mainly S1 segment) shows hypertrophy and degeneration or regeneration changes $(\times 400)(D)$. Urinary tubules from the lysine group $(\times 100)(E)$, urinary tubule (mainly S3 segment) shows degeneration or desquamation changes and hyaline casts are seen in the urinary tubules $(\times 400)(\mathrm{F})$. 
icological evaluations concerning lysine-induced acute renal failure in dogs.

In this study, animals in the lysine group had severe clinical signs (vomiting, decreased locomotor activity, body weight, and food consumption, increased water consumption), suggestive of hyperammoniemia. Lysine may affect catabolism, as shown by the severe increase in BUN, CRN, and ammonia from Day 1. It was reported that lysine induced an inhibitory effect on the urea cycle in normal volunteer subjects (Kato et al., 1987). Lysine is known to be a powerful competitive antagonist to arginine (O'Dell and Savage, 1966; Kato et al., 1987), to inhibit liver arginase activity (Cittadini et al., 1964), and to increase the liver arginine concentration (Statter and Russell, 1978). Here, the lysine concentration in plasma was $3365 \mathrm{mg} / \mathrm{ml}$ (mean value) and was approximately 140 times higher than that of the saline group. Moreover, the plasma concentration of arginine, ornithine, and citrulline increased in the lysine group, reflecting inhibited arginase activity. Therefore, the major mechanism of the lysine-induced hyperammoniemia in this study may be related to the inhibitory effect of lysine against arginase activity in the urea cycle.

Similarly, in this study, infusion of lysine for three consecutive days increased the urinary TP and ALB. Lysine also increased urinary G-GTP (Day 1) and NAG (Days 1 and 2). It has been reported that lysine induces albuminuria (Zager et al., 1983). Urinary G-GTP (Greco et al., 1985; Rivers et al., 1996) and NAG activities (Higashiyama et al., 1983; Nakamura et al., 1983) are thought to be sensitive and reliable markers for acute tubular damage in dogs, and are the origin of proximal convoluted tubule epithelium cell (Clemo, 1998; Sugita and Yakata, 1999; Yamada and Yakata, 1999). These findings suggest that lysine-induced urinary tubule obstruction may occur in the proximal convoluted tubule epithelium.

Lysine induced urinary tubule obstruction with moderate lesion of degeneration or desquamation with hyaline casts (mainly the S3 segment) in this study. Tubular damage in rats (flattening of renal tubular cells and brush border, proximal tubular cell vacuolization, and isolated tubular cell necrosis) was observed in a previous report (Zager and Venkatachalam, 1983). The mechanism of lysine-induced acute renal failure is considered a result of lysine producing a decrease in renal blood flow and thus causing urinary tubular obstruction (Racusen et al., 1985a). Moreover, Racusen et al. (1985b) demonstrated that lysineinduced urinary tubule necrosis was the earliest patho- logic change (intratubular proteinaceous debris, desquamation of individual tubular epithelial cells, hyaline casts, and tubular regeneration) indicating acute lysine infusion in rats. Therefore, mechanisms of lysine-induced tubular obstruction in dogs may be related to renal dysfunction since pathological changes occur similar to those in rats (Racusen et al., 1985b; Zager and Venkatachalam, 1983).

We considered as follows that the hyperammoniemia was not observed in the Morihepamin group. Morihepamin is an amino acid injection for hepatic insufficiency, and the feature of the amino acid composition of Morihepamin is the point of increasing the quantity of the arginine content which promotes ammonia metabolism, and decreasing the quantity of ammonia original nature amino acid. The amino acid in plasma on Day 3 after the start of infusion showed the pattern that reflected amino acid composition of Morihepamin (Table 4). In the Morihepamin group, the plasma amino acid concentration had two-fold increases compared with the saline group that had increased proline, valine, isoleucine, leucine, and arginine. These results that were considered compoundrelated changes showed similar profiles of plasma amino acid concentration in dogs and normal volunteer subjects (Amino et al., 1990; Sanjo et al., 1991). Although the two-fold increase in plasma concentration of the arginine and ornithine compared with the saline was observed in the Morihepamin group, these changes are not related changes accompanied by an increase in ammonia. The increase in arginine was considered to reflect the amino acid composition of Morihepamin, but the details were unknown although it was considered that the increase in ornithine was caused when Morihepamin activated the urea cycle in the liver. Therefore, the hyperammoniemia was not observed in the Morihepamin group, since the pharmacological effect of Morihepamin has a potent ammonia lowering action in the plasma and brain, and that the effect of this solution on ammonia metabolism may occur via the activation of the urea cycle system in the liver (Kokuba et al., 1990). An increase in BUN in the Morihepamin group demonstrated non-related changes of acute renal failure because urinary tubule obstruction was not observed in the urinalysis and histopathology of the Morihepamin group. Hypertrophy of the urine tubule epithelium in the Morihepamin group was not similar to the severe changes of lysine-induced kidney obstruction. A slight increase in urinary NAG was observed in the Morihepamin group, with a higher concentration on Day 3 after the start of infusion compared 
Lysine-induced acute renal failure in dogs.

with the saline group. However, since the change was slight and almost comparable to pre-infusion values for each group, it is considered a change unrelated to kidney damage.

First, the results obtained in this study demonstrated that lysine-induced acute renal failure produced changes in the parameters (BUN, CRN, Urinary GGTP, NAG, TP, and ALB) in dogs. Moreover, lysineinduced urinary tubule obstructions were found in the S3 segment of the proximal convoluted tubule in the kidney. We conclude that lysine is nephrotoxic in dogs. The nephrotoxicity of lysine may be directly related to tubular toxicity and tubular obstruction in dogs. Second, the lysine-induced hyperammoniemia was observed as the toxicity of the high-dose lysine infusion in dogs. The lysine prevents urea formation in the urea cycle by inhibiting arginase, with a corresponding increase in ammonia formation, and causes the hyperammoniemia. These results demonstrated that monitoring of the nephrotoxicity-related biomarkers is important by long-term clinical use of lysine.

\section{ACKNOWLEDGMENT}

We thank Dr. Tetsuro Taneike and Dr. Takio Kitazawa from Rakuno Gakuen University for their excellent advice and Dr. Paul Langman of Chugai Pharmaceutical Co., Ltd. for his assistance with English usage.

\section{REFERENCES}

Amino, M., Fukuda, M., Tomita, M., Shimizu, M., Uchida, G. and Hayashi, T. (1990): Metabolism of amino acids after intravenous administration of MSH-2, an amino acid solution for hepatic encephalopathy in dogs. Jpn. Pharmacol. Ther., 18, 129-136.

Cittadini, D., Pietropaolo, C., de Cristofaro, D. and D'Ayjello-Caracciolo, M. (1964): In vivo effect of L-lysine on rat liver arginase. Nature, 203, 643-644.

Clemo, F.A.S. (1998): Urinary enzyme evaluation of nephrotoxicity in the dog. Toxicol. Pathol., 26, 29-32.

Greco, D.S., Turnwald, G.H., Adams, R.,Gossett, K.A., Kearney, M. and Casey, H. (1985): Uriary $\gamma$-glutamyl transpeptidase activity in dogs with gentamicin-induced nephrotoxicty. Am. J.Vet. Res., 46, 2332-2335.

Gougoux, A., Lemieux, G. and Vinay, P. (1978):
Bicarbonaturic effect of lysine in the dog. Kidney Int., 14, 215-227.

Hayashi, S., Chone, Y., Kohge, M., Kurisu, K. and Kawaguchi,Y. (1992): Toxicology of an amino acids solution for renal insufficiency (TO-70) (V) - Toxicity study of TO-70 in beagle dogs by intravenous infusion for 5 consecutive weeks -. Jpn. Pharmacol. Ther., 20, 61-83.

Higashiyama, N., Nishiyama, S., Itoh, T. and Nakamura, M. (1983): Effect of castration on urinary $N$-acetyl- $\beta$-D-glucosaminidase levels in male beagles. Ren. Physiol., 6, 226-231.

Horio, M. and Orita, Y. (1999): Blood urea nitrogen, non protein nitrogen. Nihonrinsyo, 57, 546-548.

Ikeda, Y., Fukunaga, H., Imai, N., Nohara, M., Taguchi, M., Kawabata, K., Hanada, S. and Iwai, M. (1995): Toxicity studies of GA-1080, a new TPN solution (4): Single dose toxicity study of GA-1080 (H) in dogs. Jpn. Pharmacol. Ther., 23, 57-81.

Kato, T., Sano, M. and Mizutani, N. (1987): Inhibitory effect of intravenous lysine infusion on urea cycle metabolism. Eur. J. Pediatr., 146, 56-58.

Kokuba, Y., Chaki, H., Makita, I., Ikemoto, H., Terashima, K., Shimamura, H. and Sato, M. (1990): Pharmacological study of an amino acid solution (MSH-2) for hepatic encephalopathy (IV) -The mechanism of MSH-2 on ammonia metabolism in portacaval anastomosis rats-. Jpn. Pharmacol. Ther., 18, 4323-4331.

Malis, C.D., Racusen, L.C., Solez, K. and Whelton, A. (1984): Nephrotoxicity of lysine and of a single dose of aminoglycoside in rats given lysine. $\mathrm{J}$. Lab. Clin. Med., 103, 660-676.

Nakamura, M., Itoh, T., Miyata, K., Higashiyama, N., Takesue, H. and Nishiyama, S. (1983): Difference in urinary $N$-acetyl- $\beta$-D-glucosaminidase activity between male and female beagle dogs. Ren. Physiol., 6, 130-133.

Newburgh, L.H. and Marsh, P.L. (1925): Renal injuries by amino-acids. Arch. Int. Med., 36, 682711.

O’Dell, B.L. and Savage, J.E. (1966): Argine-lysine antagonism in the chick and its relationship to dietary cations. J. Nutr., 90, 364-370.

Racusen, L.C., Finn, W.F., Whelton, A. and Solez, K. (1985a): Mechanisms of lysine-induced acute renal failure in rats. Kidney Int., 27, 517-522.

Racusen, L.C., Whelton, A. and Solez, K. (1985b): Effects of lysine and other amino acids on kidney structure and function in the rat. Am. J. 
Pathol., 120, 436-442.

Rivers, B.J., Walter, P.A., O’Brien, T.D., King, V.L. and Polzin, D.J. (1996): Evaluation of urine gamma-glutamyl transpeptidase-to-creatinine ratio as a diagnostic tool in an experimental model of aminoglyoside-induced acute renal failure in the dog. J. Am. Anim. Hosp. Assoc., 32, 323-336.

Sanjo, K., Sumio, M., Shishido, R. and Kanbayashi, S. (1991): Phase 1 study of MSH-2 (Amino acid solution for hepatic encephalopathy. Jpn. Pharmacol. Ther., 19, 175-193.

Snedecor, G.W. and Cochran, W.G. (1967): In Statistical Methods. 6th ed. The Iowa State University Press Ames, Iowa.

Statter, M. and Russell, A. (1978): Competitive interrelationships between lysine and arginine in rat liver under normal conditions and in experimental hyperammonemia. Life Sci., 22, 2097-2102.

Steel, R.G.D. and Torrie, J.H. (1980): Principles and
Procedures of Statistics, 2nd ed. McGraw-Hill Book Company, New York.

Sugita, O. and Yakata, M. (1999): Urinary $N$-acetyl- $\beta$ D-glucosaminidase. Nihonrinsyo, 47, 363-365.

Weinberg, J.M. (1990): The effect of amino acids on ischemic and toxic injury to the kidney. Seminars in Nephrology, 10, 491-500.

Yamada, T. and Yakata, M. (1999): Urinary $\gamma$ glutamyltranspeptidase. Nihonrinsyo, 47, 376378.

Zager, R.A., Johannes, G., Tuttle, S. E. and Sharma, H. M. (1983): Acute amino acid nephrotoxicity. J. Lab. Clin. Med., 101, 130-140.

Zager, R.A. and Venkatachalam, M.A. (1983): Potentiation of ischemic renal injury by amino acid infusion. Kidney Int., 24, 620-625.

Zweig, J.I. (1973): Effects of lysine on ammonia formation, hydrogen ion, and potassium ion balance: A review and hypothesis. Clin. Chem., 19, 943-949. 